\title{
Farmer's Perception Regarding Soil Health Card in Varanasi District of Uttar Pradesh, India
}

\author{
Rakesh Kumar Mishra*
}

Awas Vikas Colony Pandeypur Varanasi, India

*Corresponding author

\section{A B S T R A C T}

\section{Keywords \\ Soil health card, Nutrient deficiency, Crop production \\ Article Info \\ Accepted: \\ 15 January 2021 \\ Available Online: \\ 10 February 2021}

The study was conducted in Varanasi district of Uttar Pradesh during 2019. Total sixteen villages of two blocks namely Harhua and Kashi Vidhya Peeth block were selected for the study. Total 174 respondents from sixteen villages were selected randomly. The data were collected through personal interview method with the help of pre-structured schedule designed with the objective of finding out awareness level and perception regarding soil health card. From the data it can be revealed that around 131 respondents ( 75.58 per cent) were aware about the soil health card and around 119 respondents were uses the recommended doses of fertilizer. The finding further reveals that approximately 29.04 per cent card holder were motivated to take their soil test because they want to increase their soil health due to excess use of fertilizers soil becomes infertile and the farmer did not able to identify the nutrient deficiency in the soil which results in a decrease in crop production.

\section{Introduction}

In India, the agricultural sector occupied a dominant position in the country's economy, the agricultural sector contribute about 14 per cent of GDP and about one- fifth of foreign exchange (Makadia et al., 2017). The agricultural sector provides employment to a huge percent i.e. 58.2 per cent (www.indiancensus, 2001) of the total labor force in India. The extreme challenge problem for India was the growth rate of food grains production which was lower than the population growth rate. The growing population puts enormous pressure on the available natural resources and infrastructure, which become more and more fragile. The soil health plays an important role in ensuring the sustainable growth of agricultural production. However, degrading soil health had become a major cause of concern, which has led to sub-optimal utilization of farm resources (Chowdhary and Theodore, 2016). Soil testing started in one form or the other, as soon as man became interested in how plants grow. It became a very useful tool for the quick determination of the soil fertility status to suggest fertilizer recommendations in the soil for various crops and providing information for the cropping sequences as well as recommendations for the soil amendment required (Das et al., 2017). 
In view of large number of productive technologies available everywhere in the country, to know perception of farmers about this technology is very important for extension workers for the adopting technology. SHC is one of important approach in agriculture because it is key elements for the sustainable production is soil (Das et al., 2017). The major component in soil are mineral, organic matter, water and air, the proportions in which they vary from each other form a system for plant growth. Farmers are resorting to addition of more and more fertilizers to obtain higher yields but as a result continued degradation of natural resources under intensive agriculture and also declining the productivity and stagnation in food grains production in India.

The soil health and fertility was the foundation for the sustainable profitability to the farmers. By using optimal doses of fertilizers and suitable cropping pattern which was scientific recommendation was the first step towards sustainable farming. Talking about the soil testing it was a science based on time-tested tool for the assessment of soil fertility and for the nutrient amendment recommendations of the soil (Padmaja and Angadi, 2018) with increase fertilizer use efficiency or appropriate use of fertilizer for specific soils and crops, it is necessary to have report on soil testing on the basis of soil testing report; farmer can know about information regarding their soil health recommendation regarding fertilizer. The Government of India has done a lot towards improving the fertility of soil in villages for agriculture. But there are some shortcomings. In the existing system, government officials known as Krushisahayaks (Agro-assistants) are assigned to each taluka (sub-district). It is the responsibility of these officials to collect the soil samples from the farmers in the given area. These soil samples are then tested in the laboratory and based on the results of the soil test report recommendations, like the type and amount of fertilizer suited to the crop, are manually generated by experts in the Department of Agriculture (Kalekar et al., 2018)

\section{Materials and Methods}

The present chapter deals with the methods and procedures used for the study. The different steps that were undertaken are listed below and the details under each step are explained in the succeeding part of the chapter. This chapter has been divided into the following subheads:

\section{Selection of the study area}

\section{Selection of the state}

Uttar Pradesh is the most populous state in India as well as the most populous country subdivision in the world. Uttar Pradesh, with a total area of 243,290 square kilometers $(93,935 \mathrm{sq} \mathrm{mi})$, is India's fourth-largest state in terms of land area (www.wikipedia.in). Uttar Pradesh is divided into 75 districts under 18 divisions. Uttar Pradesh is the second-largest economy in India after Maharashtra, with an estimated gross state domestic product of ₹ 14.89 lakh crore and agriculture is the leading occupation in Uttar Pradesh (www.wikipedia.in). Uttar Pradesh was selected purposively because of having a maximum number of soil health card holders $(31,559,349$ persons) as per the list provided by soil testing laboratory of Department of Farmers Welfare and Agriculture Development, Uttar Pradesh.

\section{Selection of district}

Varanasi district was selected purposely for the present study. The district has eight development blocks viz. Arajiline, Baragaon, Chiraigaon, Cholapur, Harhua, Kashi 
VidhyaPeeth, Pindara, Sewapuri, and 1329 villages.

\section{Selection of block}

Varanasi district comprises of eight development blocks viz., Arajiline, Baragaon, Chiraigaon, Cholapur, Harhua, Kashi VidhyaPeeth, Pindara, Sewapuri. Out of these 8 blocks, two blocks namely Kashi VidhyaPeeth and Harhua were selected purposively for the present study.

\section{Selection of villages}

Out of two blocks, a total sixteen villages namely Akhileshpur, Bhagwanpur, Basdevpur, Baksara, Muradev, Naipurakalan, Newada, Chhatripur, Pandeypur, Parmanandpur, Holapur, Hatiya, Chukhepur, Susuwahi, Tarapur and Tikari were selected purposively for the study.

\section{Selection of respondent}

Out of 16 villages, 174 respondents were selected purposely for the study (Table 1).

\section{Selection of variables, measurements,} scoring procedure and categorization

For the study purpose eight independent variables namely age, gender, education, land holding size, annual income, mass media exposure, social participation, motivation and awareness about soil health card were selected for analyzing their relationship with the dependent variable i.e. perception regarding soil health card (Table 2).

\section{Description of variables}

\section{Age}

Age was operationalized as the number of years an individual had completed at the time of interview and was measured as per the actual chronological age of an individual. On the basis of mean and standard deviation, age was categorized into three categories young, middle and old (Table 3 ).

\section{Gender}

It refers to the differences in man and woman in terms of role and status in society, values, attitude and other socio-psychological variables. It was categorized in two categories i.e. male and female.

\section{Education}

It refers to the formal education attained by an individual. All the respondents were classified into seven groups according to the number of years of their formal education (Table 4).

\section{Land holding size}

The land holding is the area of land possessed by an individual for the purpose of cultivation. The respondents were categorized into five categories viz.-Marginal, Small, Small-medium, Medium and large (Table 5).

\section{Annual income}

The annual income from all the sources of respondents was collected. On the basis of the scores obtained by each respondent, they were categorized as follows using mean and standard deviation (Table 6).

\section{Awareness about the utility of soil health card}

Awareness is the ability to directly know and perceive, to feel or to be conscious of events, objects, thoughts, emotions or sensory pattern. An important dimension of the study was to know the awareness of the farmers about soil health card. For the present study, it 
was operationalized as the awareness level of respondents about the utility of soil health card. For measuring this variable, the respondents were asked whether they have any knowledge about soil health card and its benefits.

Further, to cross-check the knowledge of respondents regarding the information provided in the soil health card, the respondents were asked some questions based on the content available in the soil health card and based on their answer, respondents were classified into yes and no.

\section{Source of data used for the study}

\section{Primary data}

The respondents of the selected villages were the primary source of data collection. The primary data was collected through a well structured and pre-tested interview schedule. The researcher personally met the respondents and explained to them about the purpose of the study. The data were collected and recorded in a free and frank atmosphere where the interviewer and interviewee had a good report.

\section{Secondary data}

The needed secondary data were collected from the various Government offices like the Department of Farmer Welfare and Agriculture Development, Tehsil office, Block Development Offices, magazines, publications, etc.

\section{Instrument of data collection}

The interview schedule was designed for collecting the relevant information of the selected variable. The questions in the interview schedule framed were simple, clear and directly related to the purpose of the study and were arranged in a logical sequence. All the farmer respondents were personally interviewed by the researcher in the study area. The respondents were assured that the information given by them would be kept confidential and it would only be used for the academic purpose.

\section{Validity and reliability of instrument}

In order to study the perception of respondents regarding soil health card, a list of statements was developed after consulting various literature, books, journals, etc.

\section{Analytical procedure (Mukati et al., 2018)}

Data collected were qualitative as well as quantitative. The quantitative data were interpreted in terms of percentage and qualitative data were tabulated on the basis of approved categorization method as described earlier. The following statistical techniques were used in the study:

\section{Frequency}

This measure was used to know the distribution pattern of respondent's variable wise and to categorize the problems perceived by respondents in order of importance.

\section{Percentage}

This measure was used for simple comparisons.

$P=\frac{X}{N} * 100$

Where;

$\mathrm{P}=$ Percentage

$\mathrm{X}=$ Frequencies

$\mathrm{N}=$ Total number of respondent 


\section{Mean}

The arithmetic mean is the sum of the scores divided by their number. This measure was used to categorize the dependent and independent variables into low, medium and high categories.

$X=\sum_{i=1}^{n} X i / N$

Where,

$\mathrm{X}=$ Mean

$\Sigma x i=$ Sum of all the pairs in a distribution

$\mathrm{N}=$ Total number of items involved.

\section{Standard deviation}

This measure was used to categorize the dependent and independent variables into low, medium and high categories.

$$
s=\sqrt{\frac{\sum(x-\bar{x})^{2}}{n-1}}
$$

Where,

$\mathrm{S}=$ Standard Deviation

$\mathrm{x}=$ deviation of the score from mean

$\mathrm{n}=$ number of observation

\section{Correlation test}

Karl Pearson's simple correlation test was used to find out the nature of the relationship between independent and dependent variables.

$r_{x y}=\frac{\text { Covariance } x . y(p)}{\sqrt{\text { Variance } x(p) x \text { Variance } y(p)}}$

Where,

rxy $=$ Correlation coefficient between character $\mathrm{x}$ and $\mathrm{y}$
$\operatorname{Cov}(\mathrm{x}, \mathrm{y})=$ Co-variance of character $\mathrm{x}$ and $\mathrm{y}$

$\mathrm{V}(\mathrm{x})=$ Variance of character $\mathrm{x}$, and

$\mathrm{V}(\mathrm{y})=$ Variance of character $\mathrm{y}$

t-test

t-test was used to test the significance of correlation coefficient.

\section{Hypotheses (Mukati et al., 2018)}

1. There is no relationship between age of the respondents and perceived importance of soil health card;

2. There is no relationship between gender of the respondents and perceived importance of soil health card;

3. There is no relationship between education of the respondents and perceived importance of soil health card;

4. There is no relationship between the size of land holding of the respondents and perceived importance of soil health card;

5. There is no relationship between the annual income of the respondents and the perceived importance of soil health card; and

6. There is no relationship between awareness about soil health card of the respondents and perceived importance of soil health card.

This chapter deals with the analysis and interpretation of collected data which were collected from the sample of 174 soil health card holders through the pre-tested structured interview schedule. The calculation was made on frequency, percentage basis, mean, standard deviation and correlation test were also applied. The data were processed keeping in view the objectives of the study. The findings are presented under the following section: 
To study farmer's socio-personal, economic, communication and psychological profile in Varanasi district of Uttar Pradesh;

To find out awareness level and perception of farmers regarding SHC in the study area;

To aware about the utility of SHC in the study area; and

To analyze the constraints expressed by farmers in the utilization of SHC.

\section{Results and Discussion}

Objective-I: Socio-personal, economic, communication and psychological profile of respondent

\section{Age wise distribution of respondents}

Age denotes the chronologically completed calendar years by the respondents. Physical and psychological development of an individual is related to his/her age. Age influences the behavior of an individual by exposing to varied situations for a number of items. Therefore, the age of the farmers was considered as an essential aspect in the study.

Table 7 reveals that out of total soil health card holder, 59.19 per cent were of middle age group followed by young (39.08 per cent) and old (01.73 per cent) age group. Thus, it may be inferred from the data that the maximum percentages of soil health card holders (59.19 per cent) were belonging to the middle age group.

\section{Gender wise distribution of respondents}

A perusal of Table 8 reveals that out of total soil health card holders, 84.48 per cent were male and 15.52 per cent were female. Thus, it may be inferred from the data that the maximum percentages of soil health card holders (84.48 per cent) were men.

\section{The education level of respondent}

Table 9 shows that 27.01 per cent were having education up to middle school, followed by were able to read and write (17.81 per cent), illiterate (14.94 per cent), primary education (14.36 per cent), high school education (09.77 per cent), higher secondary (6.32 per cent), graduation (05.74 per cent) and 04.05 per cent had postgraduation education. Thus, it can be inferred from the data that the maximum percentage of the soil health card holder were having middle school education (27.01 per cent).

\section{Land holding}

Landholding size-wise distribution of respondents is presented in Table 10. A total sample size of the present study was 174 . Out of total soil health card holders largest sample size was falls in the category of semi-medium category ( 2 to 4 hectare) followed by a small category of farmers ( 24.13 per cent), marginal farmers (23.56 per cent), and medium category of farmers (22.41 per cent) and lowest for large size of farmers with 4.04 per cent. Thus, it can be inferred from the data that the maximum percentage of the soil health card holder were having a smallmedium size of land holding ( 25.86 per cent).

\section{Annual income}

Table 11 reveals that out of total soil health card holder 47.14 per cent were having a medium level of annual income, followed by 35.05 per cent were in the low-income category and only 17.81 per cent of the soil health card holder was belonged to highincome group. Hence on the basis of the data, it can be concluded that the maximum percentage (47.14 per cent) of the soil health card holders were having a medium level of annual income. 


\section{Mass media exposure}

It is evident from Table 12 that maximum respondents were watching television i.e. 22.98 per cent. Regarding use of telephone, it was around 14.94 per cent use telephone followed by 10.53 per cent respondent using agricultural magazine and the exposure and demonstration (9.19 per cent), whereas soil health card holder attend meeting 8.04 per cent and about 7.47 percent soil card holder attend KisanMela and around 3.44 per cent farmer listen to radio.

\section{Social participation}

Social participation means the voluntary sharing in person to person and in a group to group relationship beyond the immediate household (Pathak, 2002).It is clear in Table 13 that about 91.95 per cent card holder was not a member of any social group of their area andremaining 7.47 per cent respondents were a member of social groups.

Table 14 proves that a very negligible involvement of soil card holder in institution groups i.e. only 8.50 per cent. A total sample size of the respondent was 174 . Out of total sample respondents, less than one per cent respondents were a member of the different social group.

Objective -II: Awareness level and perception of farmers regarding the utility of Soil Health Card

\section{Awareness about Soil Health Card}

Table 15 represents the awareness regarding the soil health card. A total sample size of the respondents was 174 . Out of this, nearly 75.28 per cent respondents were aware of the soil health card. It may be inferred from the data that the majority of the respondents had knowledge and understanding about the soil health cards. Further, the respondents were asked to tell something about soil health card. Accordingly respondents were asked some question such as from where did they get the information about soil health card, do they have soil health card, when was your soil tested, name the nutrients for which you have tested your soil sample, do you know when the soil sample was taken from your land, who collected the soil sample from your field, have you availed the services of mobile soil testing van, do you understand what written on soil health card, what do they understand by $\mathrm{pH}$, what is the type of their soil and many such question. Responses to such questions were recorded qualitatively. After analysis of the data, it was found that out of 174 respondents, 75.28 per cent of the respondents were aware and 24.72 per cent were not aware of the utility of soil health card made by the department and other sources.

\section{Source of information}

Further, reveal that out of 75.28 per cent of soil health card holder majority of the respondent i.e. 25.19 per cent respondents were got information regarding soil health card from the staff of Krishi Vigyan Kendra (KVK) followed by relatives and friends 20.61 per cent, SAU's 19.84 per cent. There were some private company also told about soil health card to farmers (17.55 per cent), gram mitra and gram sevak also played an important role in disseminating information about soil health card to farmers 7.63 percent and 4.59 per cent respectively the least approach to the farmer is agriculture department to farmer directly i.e. 4.59 per cent only (Table 16).

\section{Soil testing year}

The maximum soil test was done in the year 2017 (31.29 per cent) followed by the 2018 (29.77 per cent) in the year 2019 it is still 
going on and it was 17.57 per cent. In the year 2016, it was 12.21 per cent, the least soil testing was done in the year 2015 i.e. 9.16 per cent as it is the introduction year of the scheme may be the reason for less soil test (Table 17).

\section{Awareness about the conduct of the test}

Table 18 shows that 59.54 per cent farmer knows about the procedure conducted on their land for collecting a soil sample and 40.46 per cent farmers did not know when and how soil sample was collected from their agriculture field.

\section{Collection of soil sample}

As the data are shown in Table 19 out of 78 card holder the maximum soil sample was taken by the KVK staff i.e. 21.39 per cent as the KVK staff guide other farmers how to take the soil sample from the field as approximately 20.16 percent soil sample is collected by the farmer itself and approximately same per cent i.e. 20.61 per cent taken from the relative and friend also. Around 18.32 per cent of the soil sample is taken by the gram sevak followed by agriculture department i.e. 10.68 per cent and the least soil sample is collected by the gram mitra i.e. only 8.39 per cent.

\section{Awareness about Soil Testing Mobile Van}

The government provides mobile soil testing van for the test of the soil sample in the remote area where farmers were unable to go for their soil testing. About 55.75 per cent of farmer out of 131 card holders know about the mobile soil testing van and about 44.25 per cent cardholder did not know about the mobile soil testing van as there are very less availability of mobile soil testing van results in less awareness about it (Table 20).

Table.1 Selection of respondent

\begin{tabular}{|c|l|c|c|}
\hline S. No. & Name of Village & Name of Block & Number of Respondents \\
\hline $\mathbf{1 .}$ & Akhileshpur & KVP & 9 \\
\hline $\mathbf{2 .}$ & Bhagwanpur & KVP & 8 \\
\hline $\mathbf{3 .}$ & Basdevpur & Harhua & 10 \\
\hline $\mathbf{4 .}$ & Baksara & Harhua & 10 \\
\hline $\mathbf{5 .}$ & Muradev & KVP & 10 \\
\hline $\mathbf{6 .}$ & Naipurakalan & KVP & 11 \\
\hline $\mathbf{7 .}$ & Newada & KVP & 10 \\
\hline $\mathbf{8 .}$ & Chhatripur & Harhua & 14 \\
\hline $\mathbf{9 .}$ & Pandeypur & Harhua & 13 \\
\hline $\mathbf{1 0 .}$ & Parmandpur & Harhua & 18 \\
\hline $\mathbf{1 1 .}$ & Holapur & Harhua & 15 \\
\hline $\mathbf{1 2 .}$ & Hatiya & Harhua & 11 \\
\hline $\mathbf{1 3 .}$ & Chukhepur & Harhua & 6 \\
\hline $\mathbf{1 4 .}$ & Susuwahi & KVP & 11 \\
\hline $\mathbf{1 5 .}$ & Tarapur & KVP & 9 \\
\hline $\mathbf{1 6 .}$ & Tikari & KVP & 9 \\
\hline $\mathbf{1 7 .}$ & Total & & 174 \\
\hline & & & \\
\hline
\end{tabular}


Table.2 Socio-personal, economic, communication and psychological variables

\begin{tabular}{|c|l|l|}
\hline S.No. & Variables & Measurement \\
\hline & Independent variables & \\
\hline $\mathbf{1 .}$ & Age of Respondents & Chronological age (in completed years) \\
\hline $\mathbf{2 .}$ & Gender & Male/Female \\
\hline $\mathbf{3 .}$ & Education & Schedule \\
\hline $\mathbf{4 .}$ & Land holding size & In ha. \\
\hline $\mathbf{5 .}$ & Annual income & In rupees \\
\hline $\mathbf{6 .}$ & Farming experience & In years \\
\hline $\mathbf{7 .}$ & Social participation & Schedule \\
\hline $\mathbf{8 .}$ & Awareness about soil health card & Schedule \\
\hline & Dependent Variable & \\
\hline $\mathbf{1 .}$ & $\begin{array}{l}\text { Perception regarding soil health } \\
\text { card }\end{array}$ & Index was developed \\
\hline & & \\
\hline
\end{tabular}

Table.3 Age-wise distribution of respondents

\begin{tabular}{|r|l|l|}
\hline S. No. & Categories & Characteristics \\
\hline $\mathbf{1 .}$ & Young age & 18 to 34 years \\
\hline $\mathbf{2 .}$ & Middle age & 35 to 55 years \\
\hline $\mathbf{3 .}$ & Old age & 55 to Above years \\
\hline
\end{tabular}

Table.4 Education level wise classification of respondents

\begin{tabular}{|c|l|}
\hline S.No. & Categories \\
\hline $\mathbf{1 .}$ & Illiterate \\
\hline $\mathbf{2 .}$ & Only read and write \\
\hline $\mathbf{3 .}$ & Primary \\
\hline $\mathbf{4 .}$ & Middle \\
\hline $\mathbf{5 .}$ & High school \\
\hline $\mathbf{6 .}$ & Higher secondary \\
\hline $\mathbf{7 .}$ & Graduation \\
\hline $\mathbf{8 .}$ & Post Graduation \\
\hline
\end{tabular}

Table.5 Land holding size-wise classification of respondents

\begin{tabular}{|c|l|l|}
\hline S. No. & Category & Characteristics \\
\hline $\mathbf{1}$ & Marginal & (up to 1 hectare) \\
\hline $\mathbf{2}$ & Small & (1 to 2 hectare) \\
\hline $\mathbf{3}$ & Semi-Medium & (2 to 4 hectare) \\
\hline $\mathbf{4}$ & Medium & (4 to 10 hectare $)$ \\
\hline $\mathbf{5}$ & Large & $(10$ and above hectare) \\
\hline
\end{tabular}


Table.6 Income-wise distribution of respondents

\begin{tabular}{|c|l|l|}
\hline S.No. & Category & Characteristics \\
\hline $\mathbf{1}$ & Low & (up to Rs 50,000) \\
\hline $\mathbf{2}$ & Medium & (Rs 50,001 to Rs 2,00,000) \\
\hline $\mathbf{3}$ & High & (Above Rs2,00,000) \\
\hline
\end{tabular}

Table.7 Distribution of respondents according to their age

\begin{tabular}{|c|l|c|c|}
\hline \multirow{2}{*}{ S.No. } & \multicolumn{1}{|c|}{ Categories } & \multicolumn{2}{|c|}{ Soil Health Card Holder } \\
\cline { 3 - 4 } & & Number of Respondents & Percentage \\
\hline $\mathbf{1}$ & Young (18 to 34 years) & 68 & 39.08 \\
\hline $\mathbf{2}$ & Middle (35 to 55 years) & 103 & 59.19 \\
\hline $\mathbf{3}$ & Old (55 to above years) & 3 & 01.73 \\
\hline $\mathbf{4}$ & Total & 174 & 100.00 \\
\hline
\end{tabular}

Table.8 Gender wise distribution of respondents

\begin{tabular}{|c|l|c|c|}
\hline \multirow{2}{*}{ S.No. } & \multicolumn{2}{|c|}{ Categories } & \multicolumn{2}{c|}{ Soil Health Card Holder } \\
\cline { 3 - 4 } & & Number of Respondent & Percentage \\
\hline $\mathbf{1}$ & Female & 27 & 15.52 \\
\hline $\mathbf{2}$ & Male & 147 & 84.48 \\
\hline $\mathbf{3}$ & Total & 174 & 100.00 \\
\hline
\end{tabular}

Table.9 Educational status of respondents

\begin{tabular}{|c|l|c|c|}
\hline \multirow{2}{*}{ S.No. } & \multicolumn{1}{|c|}{ Categories } & \multicolumn{2}{|c|}{ Soil Health Card Holder } \\
\cline { 3 - 4 } & & Number of Respondents & Percentage \\
\hline $\mathbf{1 .}$ & Illiterate & 26 & 14.94 \\
\hline $\mathbf{2 .}$ & Only read and write & 31 & 17.81 \\
\hline $\mathbf{3 .}$ & Primary Education & 25 & 14.36 \\
\hline $\mathbf{4 .}$ & Middle School & 47 & 27.01 \\
\hline $\mathbf{5 .}$ & High School & 17 & 09.77 \\
\hline $\mathbf{6 .}$ & Higher Secondary & 11 & 06.32 \\
\hline $\mathbf{7 .}$ & Graduation & 10 & 05.74 \\
\hline $\mathbf{8 .}$ & Post-graduation & 7 & 04.05 \\
\hline $\mathbf{9 .}$ & Total & 174 & 100.00 \\
\hline
\end{tabular}

Table.10 Land holding size of soil health card holders

\begin{tabular}{|c|l|c|c|}
\hline \multirow{2}{*}{ S.No. } & \multicolumn{1}{|c|}{ Categories } & \multicolumn{2}{|c|}{ Soil Health Card Holder } \\
\cline { 3 - 4 } & & Number of Respondents & Percentage \\
\hline $\mathbf{1}$ & Marginal (up to 1 hectare) & 41 & 23.56 \\
\hline $\mathbf{2}$ & Small (1to 2 hectare) & 42 & 24.13 \\
\hline $\mathbf{3}$ & Semi Medium (2 to 4 hectare) & 45 & 25.86 \\
\hline $\mathbf{4}$ & Medium (4 to 10 hectare) & 39 & 22.41 \\
\hline $\mathbf{5}$ & Large (10 hectare and above) & 7 & 04.04 \\
\hline $\mathbf{6}$ & Total & 174 & 100.00 \\
\hline
\end{tabular}


Table.11 Annual income-wise distribution of respondents

\begin{tabular}{|c|l|c|c|}
\hline \multirow{2}{*}{ S.No. } & \multicolumn{1}{|c|}{ Categories } & \multicolumn{2}{c|}{ Soil Health Card Holder } \\
\cline { 3 - 4 } & & Number of Respondents & Percentage \\
\hline $\mathbf{1}$ & Low Income(up to Rs 50000) & 61 & 35.05 \\
\hline $\mathbf{2}$ & Medium Income(Rs50000 to 200000) & 82 & 47.14 \\
\hline $\mathbf{3}$ & High Income( above Rs 200000) & 31 & 17.81 \\
\hline $\mathbf{4}$ & Total & 174 & 100.00 \\
\hline
\end{tabular}

Table.12 Extent of utilization of mass media by soil health card holders

\begin{tabular}{|c|l|c|c|}
\hline \multirow{2}{*}{ S.No. } & \multicolumn{1}{|c|}{ Categories } & \multicolumn{2}{|c|}{ Soil Health Card Holder } \\
\cline { 3 - 4 } & & Number of Respondents & Percentage \\
\hline $\mathbf{1}$ & Television & 40 & 22.98 \\
\hline $\mathbf{2}$ & Radio & 6 & 03.44 \\
\hline $\mathbf{3}$ & Telephone & 10 & 14.94 \\
\hline $\mathbf{4}$ & Newspaper & 18 & 05.74 \\
\hline $\mathbf{5}$ & Agriculture Magazine & 16 & 10.34 \\
\hline $\mathbf{6}$ & Demonstration & 16 & 09.19 \\
\hline $\mathbf{7}$ & Exposure visit & 14 & 09.19 \\
\hline $\mathbf{8}$ & Meeting & 15 & 08.04 \\
\hline $\mathbf{9}$ & Exhibition & 13 & 08.62 \\
\hline $\mathbf{1 0}$ & KisanMela & 174 & 07.47 \\
\hline $\mathbf{1 1}$ & Total & & 100.00 \\
\hline
\end{tabular}

Table.13 Involvement of soil health card holders in social groups

\begin{tabular}{|l|l|c|c|}
\hline S.No. & $\begin{array}{l}\text { Are you a member of any } \\
\text { social group/institution }\end{array}$ & Number of Respondents & Percentage \\
\hline $\mathbf{1}$ & Yes & 14 & 08.05 \\
\hline $\mathbf{2}$ & No & 160 & 91.95 \\
\hline $\mathbf{3}$ & Total & 174 & 100.00 \\
\hline
\end{tabular}

Table.14 Involvement of soil health card holders in different sectors

\begin{tabular}{|c|l|c|c|}
\hline \multirow{2}{*}{ S.No. } & \multicolumn{1}{|c|}{ Categories } & \multicolumn{2}{|c|}{ Soil Health Card Holder } \\
\cline { 3 - 4 } & & Number of Respondent & Percentage \\
\hline $\mathbf{1}$ & Gram Panchayat & 3 & 0.005 \\
\hline $\mathbf{2}$ & Janpad Panchayat & 1 & 0.017 \\
\hline $\mathbf{3}$ & District & 4 & 0.005 \\
\hline $\mathbf{4}$ & Agriculture group & 5 & 0.022 \\
\hline $\mathbf{5}$ & social group & 14 & 0.028 \\
\hline $\mathbf{6}$ & Total & & 0.097 \\
\hline
\end{tabular}


Table.15 Awareness regarding soil health card scheme

\begin{tabular}{|r|l|c|c|}
\hline S.No. & $\begin{array}{l}\text { Do you know about Soil } \\
\text { Health Card }\end{array}$ & Number of Respondent & Percentage \\
\hline $\mathbf{1}$ & Yes & 131 & 75.28 \\
\hline $\mathbf{2}$ & No & 43 & 24.72 \\
\hline $\mathbf{3}$ & Total & 174 & 100.00 \\
\hline
\end{tabular}

Table.16 Sources of information about soil testing

\begin{tabular}{|c|l|c|c|}
\hline \multirow{2}{*}{ S.No. } & \multicolumn{1}{|c|}{ Categories } & \multicolumn{2}{|c|}{ Soil Health Card Holder } \\
\cline { 3 - 4 } & & Number of Respondent & Percentage \\
\hline $\mathbf{1}$ & SAUs & 26 & 19.84 \\
\hline $\mathbf{2}$ & Private Companies & 23 & 17.55 \\
\hline $\mathbf{3}$ & Relatives \& Friends & 27 & 20.61 \\
\hline $\mathbf{4}$ & Gram Mitra & 10 & 7.63 \\
\hline $\mathbf{5}$ & Gram Sevak & 6 & 4.59 \\
\hline $\mathbf{6}$ & Agriculture Dept staff & 6 & 4.59 \\
\hline $\mathbf{7}$ & KVK Staff & 33 & 25.19 \\
\hline $\mathbf{8}$ & Total & 131 & 100.00 \\
\hline
\end{tabular}

Table.17 Soil testing is done in different year

\begin{tabular}{|r|c|c|c|}
\hline S.No. & Year of soil test for Soil Health Card & $\begin{array}{l}\text { Number of } \\
\text { Respondent }\end{array}$ & Percentage \\
\hline $\mathbf{1}$ & 2015 & 12 & 9.16 \\
\hline $\mathbf{2}$ & 2016 & 16 & 12.21 \\
\hline $\mathbf{3}$ & 2017 & 41 & 31.29 \\
\hline $\mathbf{4}$ & 2018 & 39 & 29.77 \\
\hline $\mathbf{5}$ & 2019 & 23 & 17.57 \\
\hline $\mathbf{6}$ & Total & 131 & 100.00 \\
\hline
\end{tabular}

Table.18 Awareness about the procedure of soil sample taking

\begin{tabular}{|l|l|c|c|}
\hline S.No. & $\begin{array}{l}\text { Do you know when the soil } \\
\text { sample was taken from your land }\end{array}$ & Number of Respondent & Percentage \\
\hline $\mathbf{1}$ & Yes & 78 & 59.54 \\
\hline $\mathbf{2}$ & No & 53 & 40.46 \\
\hline $\mathbf{3}$ & Total & 131 & 100.00 \\
\hline
\end{tabular}


Table.19 Soil Sample collection by different agencies

\begin{tabular}{|r|l|c|c|}
\hline S.No. & Who collected the soil sample & Number of Respondent & Percentage \\
\hline $\mathbf{1}$ & Self & 16 & 20.61 \\
\hline $\mathbf{2}$ & Relatives and Friends & 16 & 20.61 \\
\hline $\mathbf{3}$ & Gram mitra & 07 & 8.39 \\
\hline $\mathbf{4}$ & Gram sevak & 14 & 18.32 \\
\hline $\mathbf{5}$ & Agriculture Department & 08 & 10.68 \\
\hline $\mathbf{6}$ & KVK Staff & 17 & 21.39 \\
\hline $\mathbf{7}$ & Total & 78 & 100.00 \\
\hline
\end{tabular}

Table.20 Awareness about mobile soil testing van

\begin{tabular}{|r|l|c|c|}
\hline S.No. & $\begin{array}{l}\text { Do you know about Mobile Soil Testing } \\
\text { Van }\end{array}$ & Number of Respondent & Percentage \\
\hline $\mathbf{1}$ & Yes & 73 & 55.75 \\
\hline $\mathbf{2}$ & No & 58 & 44.25 \\
\hline $\mathbf{3}$ & Total & 131 & 100.00 \\
\hline
\end{tabular}

Table.21 Understanding about what written in soil health card

\begin{tabular}{|r|l|c|c|}
\hline S.No. & $\begin{array}{l}\text { Do you understand what written } \\
\text { in the soil health card }\end{array}$ & Number of Respondent & Percentage \\
\hline $\mathbf{1}$ & Fully & 34 & 25.95 \\
\hline $\mathbf{2}$ & Partially & 40 & 30.55 \\
\hline $\mathbf{3}$ & To some extent & 43 & 32.82 \\
\hline $\mathbf{4}$ & Nothing & 14 & 10.68 \\
\hline $\mathbf{5}$ & Total & 131 & 100.00 \\
\hline
\end{tabular}

Table.22 Reason for motivation for testing soil health

\begin{tabular}{|c|l|c|c|}
\hline S.No. & Reason for motivation for testing soil health & Number of Respondent & Percentage \\
\hline $\mathbf{1}$ & Soil testing facility was provided free of cost & 25 & 19.08 \\
\hline $\mathbf{2}$ & For availing benefit under the subsidy scheme & 24 & 18.32 \\
\hline $\mathbf{3}$ & To maintain better soil health & 38 & 29.04 \\
\hline $\mathbf{4}$ & To increase crop yield & 20 & 15.26 \\
\hline $\mathbf{5}$ & $\begin{array}{l}\text { Motivation from village } \\
\text { demonstration/training/exposure visits to places }\end{array}$ & 6.10 \\
\hline & with best farming practices & & \\
\hline $\mathbf{6}$ & Peer farmers' group pressure & 5 & 3.81 \\
\hline $\mathbf{7}$ & Since it was a new technological practice & 11 & 8.39 \\
\hline $\mathbf{8}$ & Total & 131 & 100 \\
\hline
\end{tabular}


Table.23 Status of soil nutrient in soil

\begin{tabular}{|c|c|c|c|c|c|c|c|c|c|c|}
\hline 5.No. & Nutrient & $\begin{array}{l}\text { Moderately } \\
\text { Alkaline }\end{array}$ & Deficient & Very Low & Low & High & Normal & Medium & Sufficient & Total \\
\hline 1. & $\mathrm{~N}$ & - & - & 129 & 2 & - & - & - & - & 131 \\
\hline 2. & $\mathrm{P}$ & - & - & 28 & 70 & - & - & 33 & - & 131 \\
\hline 3. & K & - & - & - & - & - & - & 131 & - & 131 \\
\hline 4. & $S$ & - & 53 & - & - & - & - & - & 78 & 131 \\
\hline 5. & $\mathrm{Zn}$ & - & 71 & - & - & - & - & - & 60 & 131 \\
\hline 6. & $\mathrm{Fe}$ & - & 4 & - & - & - & - & - & 127 & 131 \\
\hline 7. & $\mathrm{Cu}$ & - & - & - & - & - & - & - & 131 & 131 \\
\hline 8. & $\mathrm{Mn}$ & - & 5 & - & - & - & - & - & 126 & 131 \\
\hline 9. & $\mathrm{~B}$ & - & 101 & - & - & - & - & - & 30 & 131 \\
\hline 10. & $\mathrm{pH}$ & 131 & - & - & - & - & - & - & - & 131 \\
\hline 11. & OC & - & - & 27 & 95 & 2 & - & 7 & - & 131 \\
\hline 12. & $\mathrm{EC}$ & - & - & - & - & - & 131 & - & - & 131 \\
\hline
\end{tabular}

Table.24 Use of recommended dose of fertilizer

\begin{tabular}{|l|l|c|c|}
\hline S.No. & $\begin{array}{l}\text { Do you use the recommended dose of } \\
\text { fertilizer }\end{array}$ & $\begin{array}{l}\text { Number of } \\
\text { Respondent }\end{array}$ & Percentage \\
\hline $\mathbf{1}$ & Yes & 119 & 90.83 \\
\hline $\mathbf{2}$ & No & 12 & 9.17 \\
\hline $\mathbf{3}$ & Total & 131 & 100.00 \\
\hline
\end{tabular}

Table.25 Reason for not applying the recommended dose

\begin{tabular}{|c|c|c|c|}
\hline S.No. & $\begin{array}{l}\text { Reason for not applying the } \\
\text { recommended dose }\end{array}$ & Number of Respondent & Percentage \\
\hline 1 & $\begin{array}{l}\text { Adequate quantity of fertilizers not } \\
\text { available }\end{array}$ & 0 & 0 \\
\hline 2 & Prices of fertilizers are high & 0 & 0 \\
\hline 3 & Lack of money to purchase fertilizers & 4 & 33.33 \\
\hline 4 & $\begin{array}{l}\text { No technical advice on method and time } \\
\text { of fertilizer application }\end{array}$ & 3 & 25.00 \\
\hline 5 & $\begin{array}{l}\text { Difficult to understand and follow the } \\
\text { recommended doses }\end{array}$ & 3 & 25.00 \\
\hline 6 & Trust on their own experiences/practices & 2 & 16.67 \\
\hline 7 & Total & 12 & 100.00 \\
\hline
\end{tabular}


Table.26 Visible changes observed

\begin{tabular}{|l|l|c|c|}
\hline S.No. & Visible change observed & $\begin{array}{l}\text { Number of } \\
\text { Respondent }\end{array}$ & Percentage \\
\hline $\mathbf{1}$ & Increase in crop yield & 19 & 15.96 \\
\hline $\mathbf{2}$ & Improvement in soil texture & 13 & 10.92 \\
\hline $\mathbf{3}$ & Improvement in crop growth & 15 & 12.60 \\
\hline $\mathbf{4}$ & Improvement in grain filling & 10 & 9.24 \\
\hline $\mathbf{5}$ & Less incidence of pest and diseases & 4 & 3.40 \\
\hline $\mathbf{6}$ & $\begin{array}{l}\text { Changes in the application of other inputs } \\
\text { like seed, labor, pesticide, etc }\end{array}$ & 7 & 5.88 \\
\hline $\mathbf{7}$ & $\begin{array}{l}\text { Cost of production on fertilizers has } \\
\text { declined }\end{array}$ & 5 & 4.24 \\
\hline $\mathbf{8}$ & Availed benefit under subsidy schemes & 8 & 6.72 \\
\hline $\mathbf{9}$ & $\begin{array}{l}\text { Adopted other modern agricultural } \\
\text { practices }\end{array}$ & 13 & 10.92 \\
\hline $\mathbf{1 0}$ & $\begin{array}{l}\text { Visit of extension officers/fellow farmers } \\
\text { has increased }\end{array}$ & 14 & 11.76 \\
\hline $\mathbf{1 1}$ & $\begin{array}{l}\text { Awareness level on agricultural practices } \\
\text { and government programs has increased }\end{array}$ & 119 & 100.00 \\
\hline $\mathbf{1 2}$ & Total & & \\
\hline
\end{tabular}

Table.27 Constraint expressed by soil health card holder

\begin{tabular}{|c|c|c|c|}
\hline S.No. & Constraints & Number of Respondent & Percentage \\
\hline 1 & $\begin{array}{l}\text { Difficulty in calculating fertilizer dose on the } \\
\text { basis of nutrient status of soil }\end{array}$ & 13 & 9.92 \\
\hline 2 & $\begin{array}{l}\text { No subsidy on inputs required by the } \\
\text { government for improving the soil quality }\end{array}$ & 28 & 21.37 \\
\hline 3 & $\begin{array}{l}\text { The time gap between soil samples taken and } \\
\text { issuing cards was too high }\end{array}$ & 24 & 18.32 \\
\hline 4 & Received soil health cards after crop harvest & 13 & 9.92 \\
\hline 5 & $\begin{array}{l}\text { Collection of soil sample was not done in the } \\
\text { presence of Farmers }\end{array}$ & 9 & 6.87 \\
\hline 6 & Problem in making soil health card & 39 & 29.79 \\
\hline 7 & Irregularity of extension services & 5 & 3.81 \\
\hline 8 & Total & 131 & 100.00 \\
\hline
\end{tabular}

Understand what written in soil health card

As the education plays an important role in the building up the nation as the result shows about maximum card holder belong to middle school i.e. 27.01 per cent whereas about 15 per cent respondents where illiterate to understand the card as it is necessary to farmer to read and understand. Based on field survey it was found that about 25.95 per cent respondents fully understood what written in the soil health card, 30.55 per cent respondents partially understood what written in soil health card. 32.82 per cent soil health card holder understand some extent and only 
10.68 per cent respondent do not understand what written in soil health card (Table 21).

\section{Objective -III: To aware about the utility of Soil Health Card}

\section{Motivation for the soil health card}

As we all know that farmer of India are very traditional in nature and they do not want to take risk because maximum farmer are belong to the marginal, small and semi-medium group and their income is also depends upon the crop production so they don't want to take risk for new method of agriculture however very few farmers are highly adaptable to new technology. Therefore, motivation is an important tool to motivate respondents for the improvement of their crop production and overall improvement of the socio-economic condition of the farmers.

Approximately 29.04 per cent card holder were motivated to take their soil test because they want to increase their soil health due to excess use of fertilizers soil becomes infertile and the farmer did not able to identify the nutrient deficiency in the soil which results in a decrease in crop production. About 19.08 per cent farmer use this scheme because it is provided free of cost or at a nominal cost, whereas 18.32 per cent card holder gone for soil testing because it is available as a subsidy scheme. Nearly 15.26 percent farmer told that after testing of soil it improves the crop yield, whereas only 3.81 per cent card holders give the reason for soil testing was farmer group pressure (Table 22).

\section{Status of soil nutrient in soil health card}

\section{Macro nutrient}

The data obtained from the farmers' soil health card and it was presented in Table 23. It was found that out of 131 sample farmers,
98.5 per cent cardholders' agricultural field having very low macronutrient i.e. nitrogen and remaining 1.5 per cent soil health card holders having low nitrogen in the soil.

In the case of phosphorus, 28 respondents were having a very low level of phosphorus in their soil, 70 having low and 33 respondents' soil having a medium level of nutrients. In the case of potash availability in soil, it was observed that all the sample farmers having a medium level of potash in their soil.

\section{Secondary nutrient}

Secondary nutrient i.e. sulphur is rating in an ample manner in soil for 78 respondents, whereas 53 respondents' soil facing a paucity of sulphur.

\section{Micro-nutrient}

In the case of micronutrient, zinc availability in the soil was deficient in 71 sample farmers. Four respondents' soil was facing iron deficiency in the soil. Out of 131 respondents, 101 respondents' soil testing report was showing the deficiency of boron.

\section{Physical parameter}

The $\mathrm{pH}$ of entire soil health card holder belongs to moderately alkaline in nature i.e. 131,whereas organic carbon maximum belongs to low rating i.e. 95 followed by very low i.e. 27 and it is least in High rating i.e. 2. The electric conductivity entirely belongs to normal rating i.e. 131 .

\section{Use of recommended dose}

The use of a recommended dose of major and micronutrients in the field, the 90.83 per cent card holder say yes they use the recommended use of major and micronutrients to the field and 9.17 per cent 
cardholder did not use the recommended dose of fertilizer (Table 24).

During the field survey, respondent told that they are not going to adopt recommended doses of the major and micronutrient. Out of total respondents, 33.33 percent farmers told that they don't have sufficient money to purchase the major and micronutrient followed by no technical advice given on method and time of nutrient application and difficult to understand and follow the recommended doses i.e. 25 per cent both and about 16.67 percent say that they have trust on their own experience (Table 25).

\section{Visible changes observed and benefits realized after the application of recommended doses}

The visible changes were observed when respondents adopted the recommended doses of micro and major nutrient and it was presented in Table 26. The maximum visible changes were observed an increase in crop yield (15.96 per cent) followed by improvement in crop growth (12.60 per cent), improvement in soil texture and maintained better soil health (10.92 per cent), awareness level on agricultural practices and government programs has increased (11.76 per cent), and least was changes in application of other inputs like seed, labor, pesticide (3.36 per cent).

\section{Objective-IV: Constraints expressed by farmers in Utilization of Soil Health Card}

According to Table 27 the maximum constrained expressed by the farmer regarding the soil health card was making soil health card (29.79 per cent) followed by no subsidy on inputs required by the government for improving the soil quality (21.37 per cent), time gap between soil samples taken and issuing cards was too high (18.32 per cent) and the least constrained by the farmer are irregularities of extension services (3.81 per cent).

\section{References}

Adesina AA, Baidu-Forson J. (1995), Farmers' perception and adoption of new agricultural technology: Evidence from analysis in Burkina Faso and Guinea, West Africa, Agricultural Economic; 13:1-9.

Chowdary K. Raghavendra and Theodore Ravi Kumar(2016), Soil Health Card adoption behaviour among beneficiaries of bhoochetana project in Andhra Pradesh, Journal of Extension Education, volume 28 (1): 39-41.

Katyal J.C., Datta S.P. and GoluiD. (2016), Global Review on State of Soil Health, Bulletin of the Indian Society of Soil Science, No. 30. Page No. 1-33.

\section{How to cite this article:}

Rakesh Kumar Mishra. 2021. Farmer's Perception Regarding Soil Health Card in Varanasi District of Uttar Pradesh, India. Int.J.Curr.Microbiol.App.Sci. 10(02): 1476-1492. doi: https://doi.org/10.20546/ijcmas.2021.1002.177 